\title{
Winter and summer blocking variability in the North Atlantic region - evidence from long-term observational and proxy data from southwestern Greenland
}

\author{
N. $\operatorname{Rimbu}^{1,2,3}$ and G. Lohmann ${ }^{1}$ \\ ${ }^{1}$ Alfred Wegener Institute for Polar and Marine Research, Bremerhaven, Germany \\ ${ }^{2}$ University of Bucharest, Bucharest, Romania \\ ${ }^{3}$ Climed Norad, Bucharest, Romania
}

Received: 25 October 2009 - Published in Clim. Past Discuss.: 13 November 2009

Revised: 4 April 2011 - Accepted: 15 April 2011 - Published: 23 May 2011

\begin{abstract}
We investigate the interannual and decadal variability of the North Atlantic atmospheric blocking frequency and distribution in connection with long-term observational and proxy records from southwestern Greenland. It is shown that warm (cold) conditions in southwestern Greenland during winter are related with high (low) blocking activity in the Greenland-Scandinavian region. The pattern of winter temperature-blocking variability is more complex than the blocking pattern associated to the North Atlantic Oscillation (NAO). We find, furthermore, that a North Atlantic blocking index is significantly correlated with seasonally resolved stable isotope records from Greenland ice cores. Both suggest a possible reconstruction of blocking variability in this region. During summer, high (low) blocking activity in the Euro-Atlantic region is associated with cold (warm) conditions in southwestern Greenland. We conclude that historical temperature records, as well as proxy data from Greenland, can be used to obtain information related to interannual and multidecadal variation of winter and summer blocking during past periods.
\end{abstract}

\section{Introduction}

Atmospheric blocking is a large-scale mid-latitude atmospheric phenomenon that induces significant climate anomalies over various regions of the North Atlantic realm. Several studies (Shabbar et al., 2001; Luo and Wan, 2005;

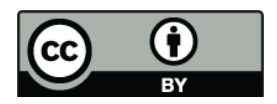

Correspondence to: N. Rimbu

(norel.rimbu@awi.de)
Barriopedro et al., 2006) detected pronounced decadal variability in atmospheric blocking frequency. Significant downward trends were identified in the number of blocked days in the Atlantic and European sectors during the period 19552002 (Barriopedro et al., 2006). Similar negative trends in the number of blocking days for the same period were detected for the northeast and northwest Atlantic sectors (Luo and Wan, 2005). Over these decreasing trends, important decadal variability in the frequency of Atlantic and European blocking were observed. Changes in both frequency and location of blocking in the North Atlantic region between 1960-1970 and 1980-1990 decades were detected (Shabbar et al., 2001). Such decadal variations characterise the blocking variability during the last decades (Barriopedro et al., 2006).

Decadal variations of blocking parameters were related to various forcing factors. Luo and Wan (2005) attributed decadal variability of blocking to decadal changes in the basic-state baroclinicity associated with the large-scale atmosphere-ocean interactions at mid-latitudes. Changes in solar radiation were attributed to decadal variations in frequency, intensity and location of atmospheric blocking (Barriopedro et al., 2008). Anomaly patterns associated to decadal variations of the Northern Hemisphere teleconnection patterns modulate frequency and position of blocking at interannual and decadal time scales (Shabbar et al., 2001; Barriopedro et al., 2006).

The blocking variability, as described in the above mentioned studies, is established using high-resolution observational data for the last decades. However, this period is too short to give a clear picture of decadal and multidecadal variation in the blocking frequency in the North Atlantic region.

Published by Copernicus Publications on behalf of the European Geosciences Union. 
The main goal of this study is to put the decadal to multidecadal variations of winter and summer blocking frequency in the North Atlantic region into a long-term context by using long-term observational and proxy data from Greenland.

Using data from the last decades, Trigo et al. (2004) found that relatively high (low) blocking activity in the AtlanticEuropean region was associated with significant increase (decrease) in daily maximum and minimum temperature over Greenland. Enhanced blocking in this region was also related with positive anomalies of precipitable water, as well as with enhanced meridional moisture transport (Trigo et al., 2004). The Greenland blocking variability was related to seaice variability (Zhifang and Wallace, 1993). Low blocking activity in Greenland is associated with high sea-ice concentration in the Baffin-Davis Strait and the Labrador Sea and low sea-ice concentration in the Barents Sea. A Greenland blocking index for the period 1955-2006 shows important decadal variations (Zhifang and Wallace, 1993; their Fig. 5). The decadal variability of atmospheric circulation, including blocking circulation, in the North Atlantic region was also investigated using long-term observational and proxy data from Greenland (Crüger et al., 2004; Rimbu et al., 2007; Rimbu and Lohmann, 2010).

Continuous long-term measurements of Greenland temperature (Vinther et al., 2006), as well as high-resolution temperature reconstructions from Greenland ice cores, are available (Crüger et al., 2004). The variability of these records is often related to the atmospheric teleconnection patterns, in particular, with the North Atlantic Oscillation (NAO) (Appenzeller et al., 1998; Hanna et al., 2006). Significant correlations between the NAO index and stable isotope time series from southern, western, eastern and central Greenland were detected (Vinther et al., 2003). Winter stable isotope records from central Greenland firn cores for the period 1959-1987 are strongly correlated with the NAO (Rogers et al., 1998). The NAO signal was also detected in stable isotope records from Greenland during the period 1778-1970 (Vinther et al., 2010). Based on the relationships between atmospheric teleconnection patterns and different proxy data from the Greenland ice cores during the observational period, valuable information related to the NAO and its associated climate anomalies during the pre-instrumental period has been obtained (e.g., Appenzeller et al., 1998). Teleconnection patterns, in particular the NAO, are related to the frequency, intensity and spatial distribution of synoptic scale atmospheric phenomena, including atmospheric blocking (e.g., Shabbar et al., 2001). Therefore, decadal variations of the atmospheric teleconnection pattern indices give information about decadal variations in the properties of synopticscale phenomena.

During winter, the NAO describes a large part of interannual to decadal variability of blocking in the North Atlantic region (Shabbar et al., 2001; Croci-Maspoli et al., 2007). However, we will show that a significant part of the blocking variability in the North Atlantic region is not directly related to the NAO variability. Furthermore, during summer the relationship between blocking and the NAO is very weak. The present study aims to investigate a direct relation between long-term observational temperature records from southwestern Greenland as well as proxy temperature records from Greenland and atmospheric blocking circulation. First, we investigate the signature of blocking on observed and reconstructed temperature of this region during the last hundred years, when reanalysis datasets are available (Kalnay et al., 1996; Compo et al., 2006, 2011; Whitaker et al., 2004). A detailed description of the relationship between blocking and the North Atlantic Oscillation during winter is presented. Based on the relationship between blocking and temperature during the observational period, we discuss the blocking patterns during the past periods as recorded by different ice cores from Greenland.

The paper is organized as follows: Data and methods are described in Sect. 2. The relationship between winter temperature variability in southwestern Greenland, atmospheric blocking and the NAO is presented in Sect. 3. The relationship between summer southwestern Greenland temperature variability and blocking is presented in Sect. 4. A discussion as well as the main conclusions follow in Sect. 5.

\section{Data and methods}

The main quantity used in our study is the published longterm observational record of air temperature $(T)$ from southwestern Greenland (Vinther et al., 2006). A merged southwestern Greenland temperature record was constructed based on early observations from three southwestern Greenland stations: Ilulissat $\left(69.23^{\circ} \mathrm{N} ; 51.07^{\circ} \mathrm{W}\right)$, Nuuk $\left(64.17^{\circ} \mathrm{N}\right.$; $\left.51.75^{\circ} \mathrm{W}\right)$ and Qaqortoq $\left(60.72^{\circ} \mathrm{N} ; 46.05^{\circ} \mathrm{W}\right)$. This temperature record covers the period 1784 to 2005 with monthly resolution. There are several gaps in this record, especially during the summer months before 1840 (Vinther et al., 2006). The winter and summer temperature time series are derived by averaging the monthly temperature during December/January/February (DJF) and June/July/August (JJA), respectively. Prior to the statistical analysis, these time series are normalised with the corresponding standard deviation. This record is available online (http://www.icecores.dk; Vinther et al., 2006).

Atmospheric blocking can be identified using a large variety of objective and subjective procedures (e.g., Barriopedro et al., 2006; Croci-Maspoli et al., 2007). Most common blocking indicators are based on the calculation of meridional $500 \mathrm{mb}$ geopotential height (Z500) gradients (e.g., Tibaldi and Molteni, 1990) or on the detection of Z500 anomaly maxima (Scherrer et al., 2006, and references therein). Other blocking indices are based on changes in latitude of the storm track or vertically averaged potential vorticity (e.g., Scherrer et al., 2006). Because we are interested in the long-term variability of blocking, we have chosen two blocking indicators based on the daily Z500 field (Tibaldi and Molteni, 1990; Scherrer et al., 2006). 
The Z500 field for the period 1908-1947 was extracted from the database of the 20th century NCEP/NCAR reanalysis project, version 1 (Compo et al., 2006, 2011), covering the period 1908-1958 with a $2^{\circ}$ latitude $\times 2^{\circ}$ longitude grid (available at http://www.esrl.noaa.gov/psd/data/gridded/ 20thC-Rean.html). The analysis is performed with the ensemble filter (Compo et al., 2006) applied on the short-term ensemble forecast of the atmospheric component of NCEP's operational Climate Forecast Model (Saha et al., 2006). The Z500 field for the period 1948-2008 was extracted from the NCEP/NCAR reanalysis project (Kalnay et al., 1996), which covers the period 1948 to present on a global grid of $2.5^{\circ}$ latitude $\times 2.5^{\circ}$ longitude horizontal resolution (available at http://www.esrl.noaa.gov/psd/data/gridded/data.ncep. reanalysis.html). These reanalysis datasets are derived from a consistent assimilation and modelling procedure that incorporates most of the available weather and satellite information. Z500 from the 20th century reanalysis project (Compo et al., 2011) was interpolated on a $2.5^{\circ} \times 2.5^{\circ}$ grid and merged with the Z500 field from the reanalysis project (Kalnay et al., 1996) to form a Z500 daily dataset with resolution $2.5^{\circ} \times 2.5^{\circ}$ that covers the period 1908-2008 (101 years). This Z500 field is used to calculate blocking indicators to be related with southwestern Greenland temperature, NAO and Greenland ice cores.

The Northern Hemisphere blocking activity is described using the Tibaldi-Molteni (TM) one-dimensional index (Tibaldi and Molteni, 1990). For each daily Northern Hemisphere Z500 map, we calculate the northern (GHGN) and the southern (GHGS) gradients as follows:

$$
\begin{aligned}
& \text { GHGS }=\left(\mathrm{Z} 500\left(\Phi_{0}\right)-\mathrm{Z} 500\left(\Phi_{\mathrm{s}}\right)\right) /\left(\Phi_{0}-\Phi_{\mathrm{s}}\right) \\
& \text { GHGN }=\left(\mathrm{Z} 500\left(\Phi_{\mathrm{n}}\right)-\mathrm{Z} 500\left(\Phi_{0}\right)\right) /\left(\Phi_{\mathrm{n}}-\Phi_{0}\right)
\end{aligned}
$$

where $\Phi_{\mathrm{n}}=80^{\circ} \mathrm{N}+\Delta, \quad \Phi_{0}=60^{\circ} \mathrm{N}+\Delta, \quad \Phi_{\mathrm{s}}=40^{\circ} \mathrm{N}+\Delta$, $\Delta=5^{\circ}, 0^{\circ}, 5^{\circ}$ latitude. A given longitude is blocked if the following conditions are satisfied for at least one value of $\Delta$ :

$$
\text { GHGS }>0 \text { and } \text { GHGN }<-10 \mathrm{~m} / \text { (degree latitude) }
$$

We calculate the ratio of the blocked days at a certain longitude and the number of season days for high and low temperature years in southwestern Greenland. Since no time-duration constraint was imposed, this ratio represents the frequency of occurrence of blocking-like patterns rather than actual synoptic blocking episodes (Tibaldi et al., 1997). Based on the longitudinal distribution of blocking-like circulation, we construct blocking indices for which both persistence and spatial extension constraints are imposed.

An extension of this blocking index is suggested by Scherrer et al. (2006). The GHGN and GHGS gradients are evaluated in each grid point using a latitudinal interval of $15^{\circ}$ instead of $20^{\circ}$ like in the case of the one-dimensional TM index described above. Following Scherrer et al. (2006) a certain grid point is considered to be blocked if the conditions
(1) are satisfied for at least five consecutive days (5-day persistence criterion). There are no exceptions allowed to this rule in contrast to some previous studies (e.g., D'Andrea et al., 1998). As a consequence, blocking frequencies are lower since only blockings that are stationary in space and uninterrupted in time are captured. These characteristics typically correspond to a mature blocking state which corresponds to persistent quasi-stationary high-pressure systems (Scherrer et al., 2006). The frequency of blocked grid points is calculated as the ratio between the number of days in a season when a certain grid point was blocked to the total number of season days. Using Z500 data north of $20^{\circ} \mathrm{N}$, the frequency of blocked grid points from $35^{\circ}$ to $75^{\circ} \mathrm{N}$ can be calculated. We compare the frequency of blocking, i.e., blocked grid points, for high and low temperature years in southwestern Greenland.

Furthermore, we use long-term reconstructions of southwestern Greenland temperatures to extend the information beyond the instrumental period. To get relevant information of blocking activity in the Atlantic region during past periods, we analyse the relationship between 14 seasonally resolved stable isotope records from Greenland ice cores (Vinther et al., 2010) and blocking variability. Therefore, long-term reconstructions of southwestern Greenland temperature can give relevant information related to the blocking activity in the Atlantic region during past periods. However, the relationship between atmospheric circulation and proxy data, in particular with stable isotope variability, is rather complex (e.g., Sodemann et al., 2008). Here we investigate the statistical relationships between 14 seasonally resolved stable isotope records from recently published Greenland ice cores (Vinther et al., 2010) and blocking variability. These are DYE3-71/79 $\left(65.18^{\circ} \mathrm{N} ; 45.83^{\circ} \mathrm{W}\right)$, DYE3-4B $\left(65.17^{\circ} \mathrm{N}\right.$; $\left.43.93^{\circ} \mathrm{W}\right)$, DYE3-18C $\left(65.03^{\circ} \mathrm{N}\right.$; $\left.44.39^{\circ} \mathrm{W}\right)$, DYE3-20D $\left(65.00^{\circ} \mathrm{N} ; 44.45^{\circ} \mathrm{W}\right)$, Milcent $\left(70.30^{\circ} \mathrm{N} ; 44.50^{\circ} \mathrm{W}\right)$, Crete $\left(71.72^{\circ} \mathrm{N} ; 37.72^{\circ} \mathrm{W}\right)$, Site A $\left(70.63^{\circ} \mathrm{N} ; 35.82^{\circ} \mathrm{W}\right)$, Site B $\left(70.65^{\circ} \mathrm{N} ; 37.48^{\circ} \mathrm{W}\right)$, Site D $\left(70.64^{\circ} \mathrm{N} ; 39.62^{\circ} \mathrm{W}\right)$, Site E $\left(71.76^{\circ} \mathrm{N} ; 35.85^{\circ} \mathrm{W}\right)$, Site G $\left(71.15^{\circ} \mathrm{N} ; 35.84^{\circ} \mathrm{W}\right)$, Renland $\left(71.27^{\circ} \mathrm{N} ; 26.73^{\circ} \mathrm{W}\right)$, GISP2 $\left(72.60^{\circ} \mathrm{N} ; 38.50^{\circ} \mathrm{W}\right)$, GRIP $\left(72.58^{\circ} \mathrm{N} ; 37.64^{\circ} \mathrm{W}\right)$ as well as the first three principal components, PC1, PC2 and PC3 of these records covering the period 1778-1970 with seasonal resolution. These records (Vinther et al., 2010) are available online (http:// www.iceandclimate.nbi.ku.dk/data/).

Furthermore, we used the first principal component of $7 \delta^{18} \mathrm{O}$ records from Greenland ice cores (Vinther et al., 2003) as a proxy for winter Greenland temperature. The ice cores PC1, referred to further as temperature reconstruction (T-REC), covers the period 1245 to 1970 with annual resolution. It was shown that the correlation between this temperature reconstruction and southern Greenland temperature during the cold season over the period 1895-1966 is 0.75 (Vinther et al., 2003; their Table 3). 


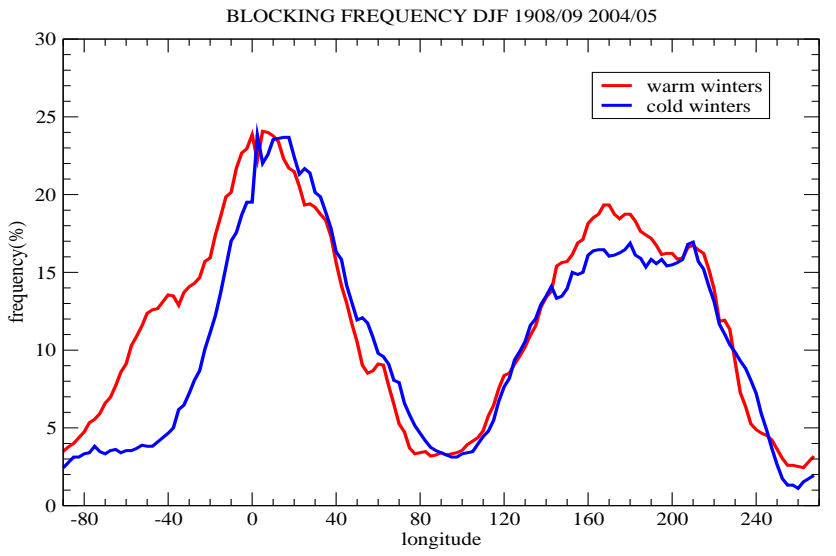

Fig. 1. Frequency composites of blocked days for warm (red) and cold (blue) winters in southwestern Greenland. Units are percentage of blocked days to total number of days per winter (90 days).

\section{Blocking variability and its relationship with southwestern Greenland temperature and NAO during winter}

\subsection{Signature of blocking in southwestern Greenland temperature}

Figure 1 shows the averaged frequency of blocking-like circulation over warm (cold) southwestern Greenland winters as a function of the longitude. A winter is classified as warm (cold) if the southwestern Greenland temperature index was higher (lower) than the mean plus (minus) one standard deviation. As noted extensively in the literature (e.g., Diao et al., 2006), the highest frequency of blocking is recorded in the northeastern Atlantic and the northeastern Pacific sectors. Both during warm and cold winters, blocking frequency is at maximum in these regions. However, the blocking frequency is higher during warm rather than during cold southwestern Greenland winters in the Atlantic sector $\left(80^{\circ} \mathrm{W}-\right.$ $\left.10^{\circ} \mathrm{W}\right)$. Outside this region, there are no significant $(95 \%$ level) differences between blocking activity during cold and warm winters in southwestern Greenland (Fig. 1).

To better assess the relationship between blocking and southwestern Greenland temperature, we define a blocking index by imposing both persistence and spatial extension constraints to blocking-like circulation regimes. The blocking index is defined as the number of days in a winter when the sector $\left(80^{\circ} \mathrm{W}-10^{\circ} \mathrm{W}\right)$ was blocked, i.e., the conditions (1) are satisfied for at least five consecutive longitudes (longitude interval is $2.5^{\circ}$ ) within this sector (spatial criteria) for at least five consecutive days (persistence criteria). Five days is the persistence threshold largely used in the literature above for which a blocking-like circulation is considered to be a blocking event (Treidl et al., 1981; Tibaldi and Molteni, 1990; D'Andrea et al., 1998). The temperature index (Fig. 2a) shows decadal variations similar to those in
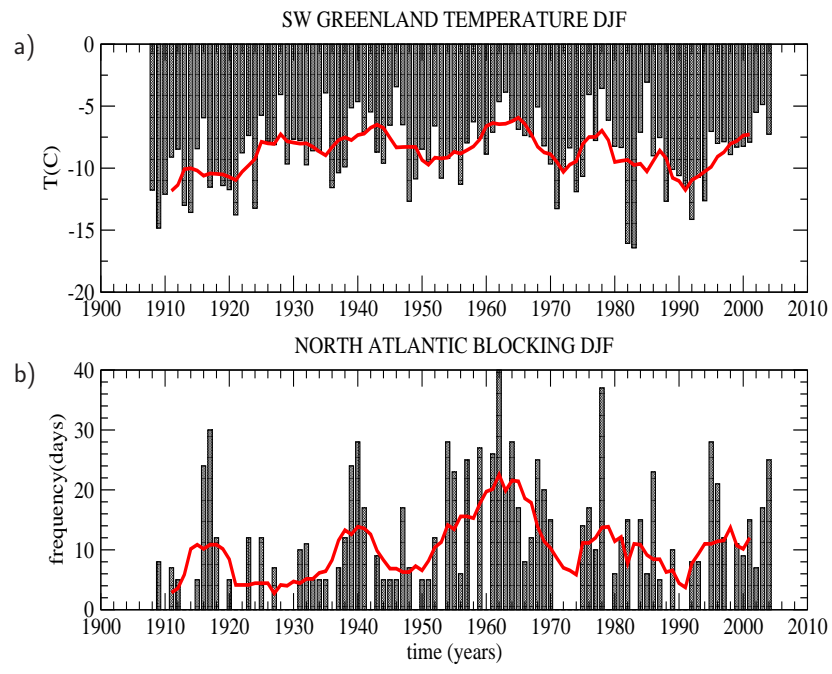

Fig. 2. (a) Southwestern Greenland winter temperature index (Vinther et al., 2006) (bar) and its decadal variation (7-year running mean) (red) for the period 1908 to 2005. (b) Blocking index (bar) and its decadal variations (7-year running mean) (red) for the same period.

the blocking index (Fig. 2b). High frequency of blocking is recorded during the decades 1910-1920, 1930-1940, 19551970, 1975-1985 and after 1995. Spectral analysis reveals a strong peak at about 20-years (not shown), a periodicity that is found in various Greenland ice cores (e.g., Hibler and Johnsen, 1979). The two time series are significantly $(95 \%)$ positively correlated both at interannual $(r=+0.42)$ and decadal $(r=+0.60)$ time scales. A cross-correlation analysis reveals that the correlation of these two indices is maximal at lag zero, both at interannual and decadal time scales.

The two-dimensional climatological winter blocking frequencies are displayed in Fig. 3. It indicates that the occurrence of blocking in the North Atlantic-European region depends both on latitude and longitude. Enhanced blocking variability is recorded from a region that stretches from Davis Strait/Labrador Sea to Scandinavia as well as another region that extends from the Azores to southern Scandinavia. Local maxima are found over southeastern Greenland and over the North Sea as well as in the Ural mountain region (Fig. 3). Similar results were obtained by Scherrer et al. (2006) (their Fig. 2).

To identify the modifications both in frequency and position of blocking, we stratified the blocking maps according to the temperature anomalies as reflected by the temperature index from southwestern Greenland. The resulting temperature-blocking composite frequencies (Fig. 4) show a clear distinction between warm and cold winters in southwestern Greenland. Warm conditions in southwestern Greenland are associated with increased blocking frequency over a broad region that extends from Greenland to southwestern Scandinavia with frequencies of $6 \%$ to $9 \%$ (Fig. $4 \mathrm{a}$ ). 

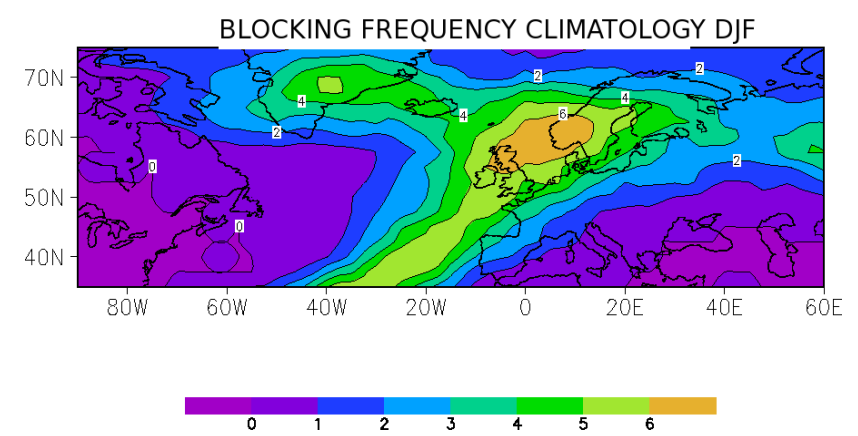

Fig. 3. Euro-Atlantic winter blocking frequency climatology of 5day persistent blocking using the Scherrer et al. (2006) blocking indicator. Units are percentage of blocked days to total number of days per winter. Period is 1908-2005.

Compared to the blocking pattern associated to the negative phase of the NAO (Scherrer et al., 2006, their Fig. 5b) the temperature related blocking pattern shows a distinct centre of high blocking frequency north of Scotland (Fig. 4a). Cold conditions in southwestern Greenland, on the other hand, are associated with enhanced blocking frequency along the Atlantic-European coast extending eastward over Europe (Fig. 4b) as well as with a significant decrease in the blocking frequency over the Greenland region. The same spatial structure of blocking characterises the positive phase of the NAO (Scherrer et al., 2006, their Fig. 5a). The map of difference of blocking frequency during high and low southwestern Greenland temperatures (not shown) shows a dipole structure with out-of-phase variations of blocking frequency anomalies from the Greenland-Scandinavian region and the Atlantic-European region. This blocking pattern is similar to that associated to the North Atlantic Oscillation (Scherrer et al., 2006). The blocking maps associated to SW Greenland temperature extremes (Fig. 4) suggest a relationship between $\mathrm{NAO}$, blocking and temperature variability.

\subsection{The relationship with the NAO}

The normalized indices with their standard deviation of southwestern Greenland temperature, blocking and NAO for the period 1908-2008 are represented in Fig. 5. A simple visual inspection of this figure reveals that in most of the years southwestern Greenland temperature and blocking indices (hereafter $T$ and $B$ indices) are in anti-phase with the NAO index. This relationship was identified in many studies (e.g., Trigo et al., 2004). However, there are years when this relationship is not seen (Fig. 5). For example during 1982-1983 winter, low southwestern Greenland temperatures comes together with high blocking activity and positive NAO. Also, there are winters like 2001-2002 when temperature, blocking and NAO indices vary in phase.

To have a qualitative image of the possible relationships between $T, B$ and NAO indices we show in Fig. 6a the
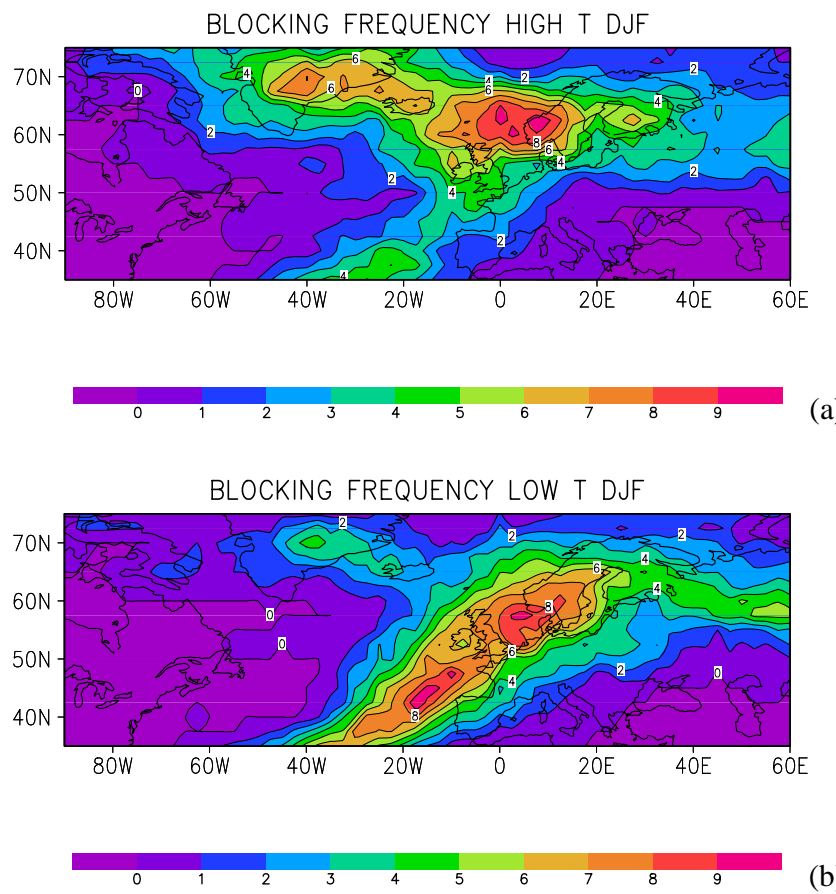

(a)

Fig. 4. (a) Blocking frequency composite for (a) high and (b) low southwestern Greenland temperatures during winter. Units are percentage of blocked days to total number of days per winter. Period is $1908-2005$.

SW GREENLAND TEMPERATURE BLOCKING NAO DJF 1908/09-2004/05
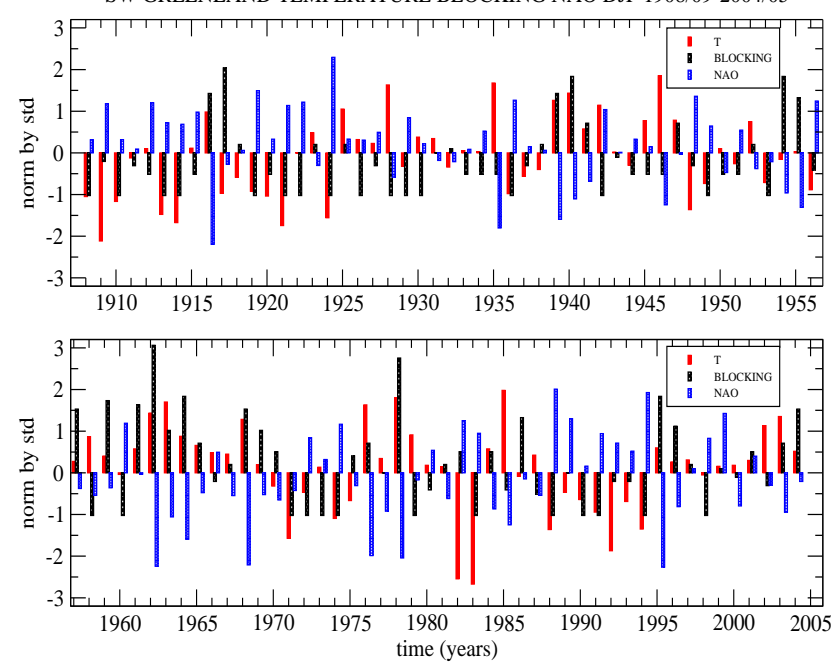

Fig. 5. Normalized winter time series of southwestern Greenland temperature (red), blocking (black) and NAO (blue) indices for the period 1908-2005.

$500 \mathrm{mb}$ circulation from 30 January 1963 when a strong blocking event occurred in the North Atlantic region. The winter of 1962-1963 is characterised by a positive temperature index, positive blocking index and negative NAO index. During this particular day, the blocking high, located 
south of Iceland, favours strong advection of warm air toward SW Greenland. The pressure near Iceland is higher than near the Azores. As pressure generally is lower in Iceland than at the Azores, it is possible to have a negative NAO index for this particular day. Pressure from southwestern Iceland (Rekyawik) and the Azores (Ponta Delgada) have been used to calculate the NAO index used in this study (Jones et al., 1997). If such events persist over long periods or if there are several such events in a certain winter, then the seasonal temperature and blocking indices will be positive and the seasonal NAO index will be negative.

During the 2001-2002 winter all three indices, i.e. $T, B$ and NAO, are positive. The blocking event from 12 December 2001 (Fig. 6b) is helpful in understanding this relationship. The blocking high is centred over Scotland. The pressure in the Iceland region is lower than in the Azores and, therefore, for this particular day, it is possible to have a positive NAO index. At the same time, the warm air is advected from the southeast toward Greenland (Fig. 6b). If this type of circulation persists or occurs frequently in a winter, then seasonal values of $T, B$ and NAO indices will be positive.

To better assess the relationship between temperature, blocking and the NAO, we performed an EOF analysis of the normalized time series of $T, B$ and NAO indices for the period 1908/1909-2004/2005 (97 winters). No filter was applied to the time series prior to the EOF analysis.

The first EOF (loadings for $T, B$ and NAO are 0.55, 0.54 and -0.62 ) describes $73 \%$ of the variance. This relationship reflects the results of previous studies (e.g., Shabbar et al., 2001; Barriopedro et al., 2006) which show that there is an out-of-phase relationship between the NAO and the frequency of the North Atlantic blocking. Negative(positive) NAO is associated with warm (cold) conditions in southwestern Greenland (Trigo et al., 2004). The PC1 of this pattern (Fig. 7d) shows interannual and decadal variations similar to those of the NAO index. The blocking pattern associated to this EOF (Fig. 7a) shows a dipolar structure with high blocking frequency in the Greenland-Scandinavian region and low blocking frequency over the western Atlantic and Europe. This pattern is similar to the blocking anomaly pattern associated to the NAO (Scherrer et al., 2006). The corresponding Z500 anomaly pattern shows a NAO-like structure (Fig. 7g).

The second EOF (19\% variance) captures the out-ofphase relationship between $T$ and $B$ and almost neutral (slightly different from zero) NAO indices (loadings $T, B$ and NAO are $-0.68,0.72$ and 0.063 ). The blocking composite map associated to this mode shows positive blocking anomalies in the Iceland region, northeastern North America and north of the Caspian Sea, as well as a negative blocking frequency anomaly in the Scandinavian region (Fig. 7b). The associated Z500 anomaly pattern (Fig. 7h) shows a regional pattern with a prominent centre of positive anomaly south of Greenland. This pattern favours advection of cold air from northwest toward southwestern Greenland. The Z500 anomalies near Iceland and the Azores, locations used for
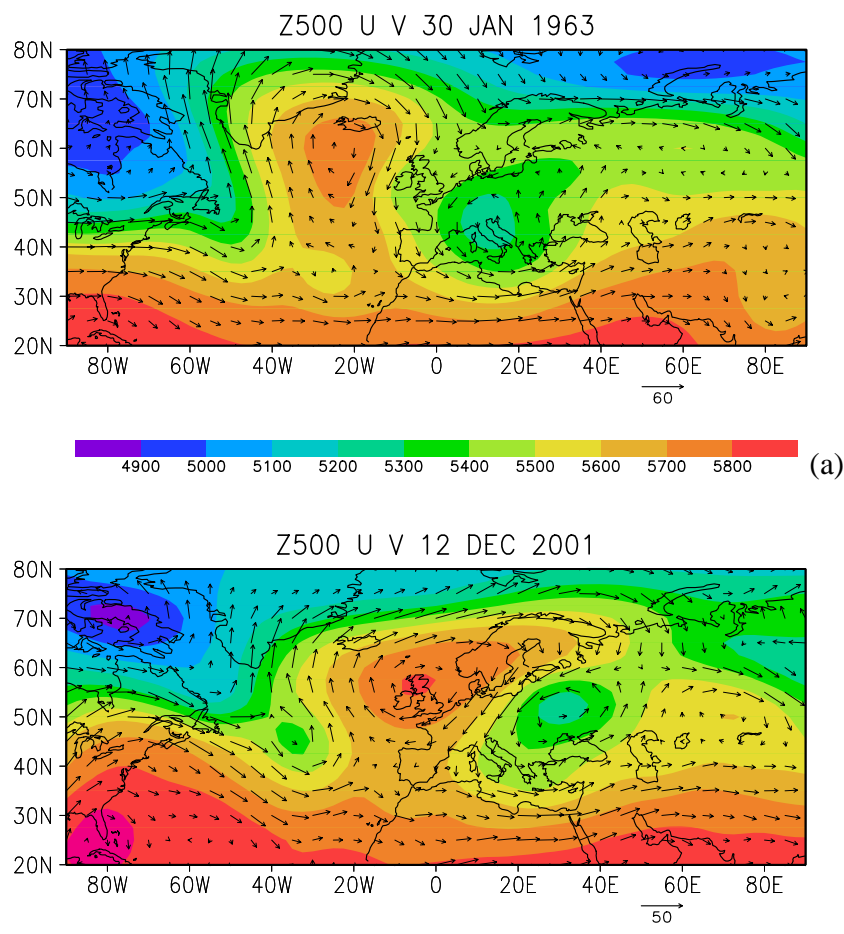

$\begin{array}{lllllllllll}4900 & 5000 & 5100 & 5200 & 5300 & 5400 & 5500 & 5600 & 5700 & 5800 & 5900\end{array}$

Fig. 6. Upper atmospheric circulation $(500 \mathrm{mb})$ for the blocking events that occurred on (a) 30 January 1963 and (b) 12 Decem-

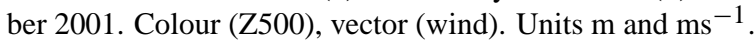

the definition of the NAO index, are relatively small which explains the close to zero values of the NAO index.

The third EOF ( $8 \%$ variance) captures in-phase variability of $T, B$ and NAO (loadings are $0.47,0.41$, and 0.77). The associate time coefficients (PC3) are represented in Fig. 7f. The associated blocking pattern (Fig. 7c) shows enhanced blocking activity along the eastern coast of the North Atlantic and low blocking activity over southwestern Greenland and southeast of Scandinavia (Fig. 7c). The corresponding circulation pattern is represented in Fig. 7i. A low pressure centre located southeast of Greenland together with the high pressure system over northern Greenland favours warm air advection from the southeast toward south and southwestern Greenland. Therefore, for such patterns, temperature in southwestern Greenland is relatively high.

\subsection{Winter blocking in proxy data}

The analysis of observational data, as presented in the previous sections, reveals that blocking activity during the observational period displays strong decadal variations. We show that southwestern Greenland temperature can be used as a proxy for North Atlantic blocking activity. But a Greenland temperature signal is detected in many records from Greenland ice cores (e.g., Vinther et al., 2010). However, proxy 

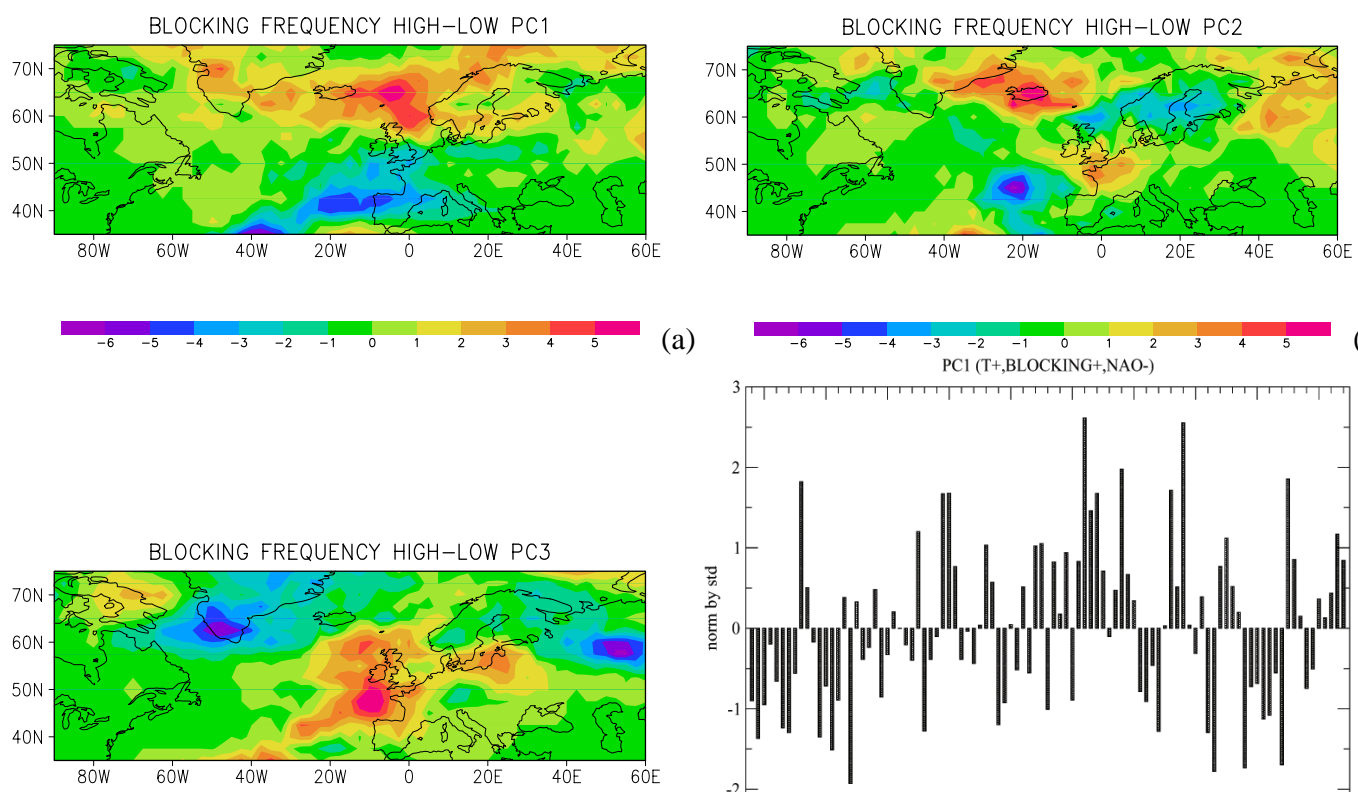

(b)
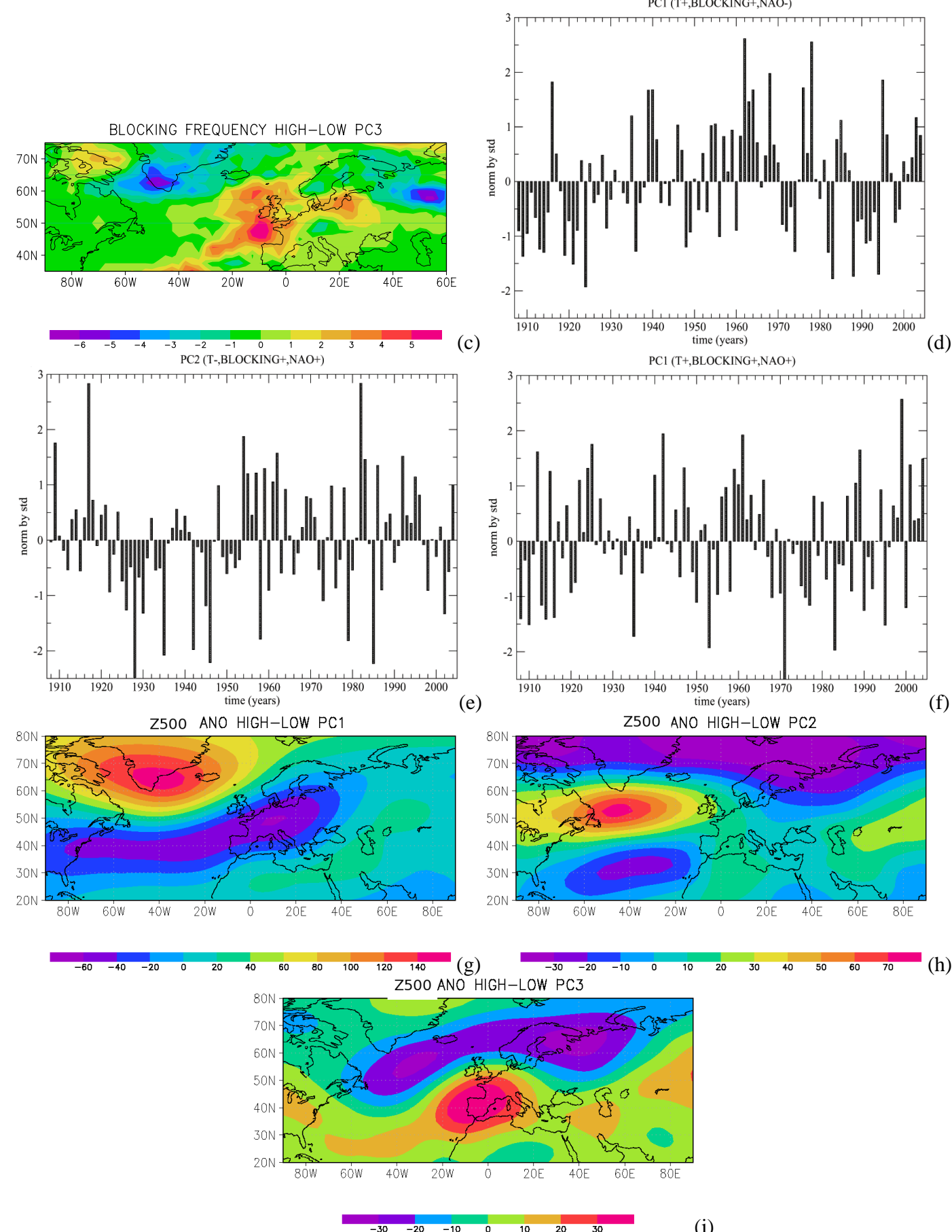

(i)

Fig. 7. Difference between (a) blocking frequency and (g) Z500 corresponding to high and low values of PC1 of $T$, blocking and NAO indices represented in (d). (b), (e) and (h) as in (a), (d) and (g) but for PC2. (c), (f) and (i) as in (a), (d) and g) but for PC3. 
data variability from Greenland ice cores, in particular stable isotope records, is related with atmospheric circulation in a very complex way (Crüger et al., 2004; Sodemann et al., 2008; Rimbu and Lohmann, 2010). Therefore, we investigate if a statistical relation between blocking frequency and stable isotope records from Greenland exists.

The correlation coefficients of our winter blocking index and the 14 recently published stable isotope records from Greenland, as well as the first three principal components (PCs) of these records (Vinther et al., 2010), are represented in Fig. 8a. These records cover the period from 1778 to 1970 with seasonal resolution. The correlation coefficients are positive for all records except SITE E, PC2 and PC3 when they have negative values. The highest correlations are obtained for DYE3-20D $(r=+0.64)$, SITE A $(r=+0.67)$ and PC1 $(r=+0.57)$. Such a relationship was expected because of the high correlation between these records and southwestern Greenland temperature (Vinther et al., 2010) which is significantly related with our blocking index. The filtered (7year running mean) time series of PC1 and the blocking index (Fig. 8b), which is similar to the observed decadal variation of SW Greenland temperature index (not shown), shows similar decadal variations over the common period 19081970. Relatively high blocking activity during 1915s, 1940s and 1960s are associated with relatively high values of the PC1 (Fig. 8b) as well as with positive anomalies at almost all stable isotope records from Greenland ice cores.

The decadal component (7-year running mean) of the southern Greenland temperature reconstruction (T-REC) (Vinther el al., 2003) is displayed in Fig. 9b. The blocking patterns associated to high T-REC values for the period 1908-1970 (Fig. 9a) and low T-REC values for the same period (Fig. 9c) are similar to those associated to the NAO (Scherrer et al., 2006) but not identical. High values T-REC indicates high blocking frequency in the Scandinavian and eastern Greenland regions (between 3 and 9\%). The blocking frequency map associated with low values of T-REC (Fig. 9c) shows three distinct centres of high blocking, one in eastern Greenland (4-5\%), one over Scandinavia (6-8\%) and the other in the Ural Mountain region (6-7\%). Note the displacement of the blocking centre from Scandinavia toward the European continent and the increase in blocking frequency in the Ural Mountain region during cold conditions (Fig. 9c) relative to warm conditions (Fig. 9a) in southwestern Greenland.

\section{Blocking variability and its relationship with southwestern Greenland temperature during summer}

Blocking circulations occur also during the summer season (e.g., Diao et al., 2006). Here we investigate how summer blocking and temperature anomalies in southwestern Greenland are related in order to put the decadal variations of North Atlantic blocking into a long-term context.
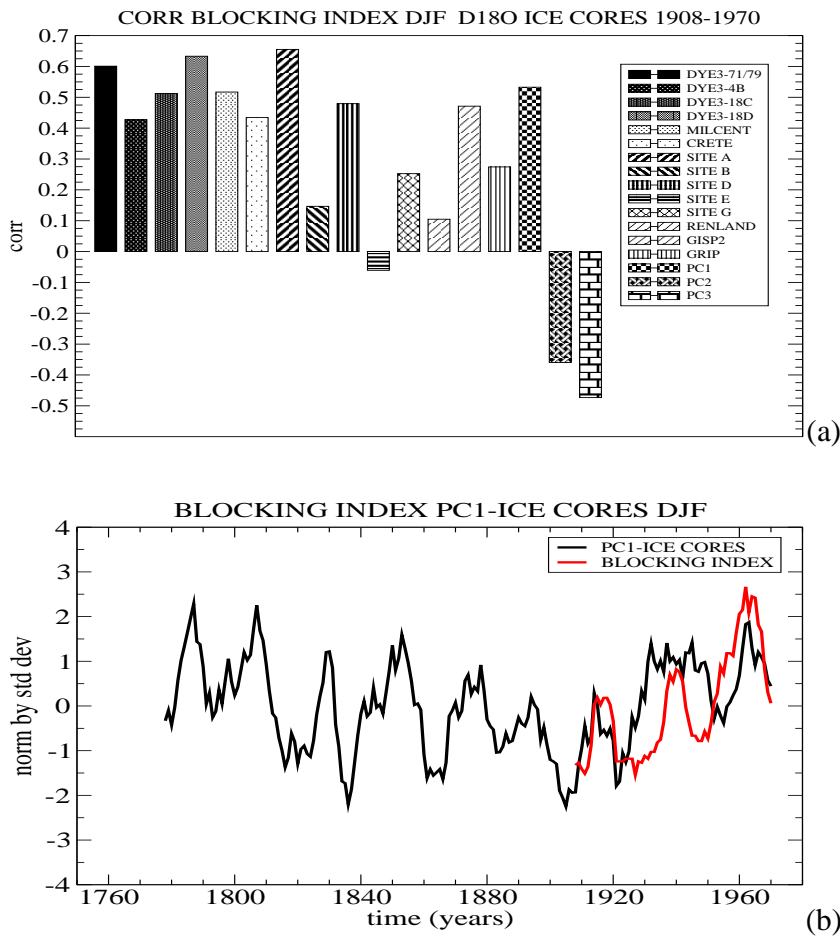

Fig. 8. (a) Correlations between winter blocking index (see text for definition) and 14 stable isotope records from Greenland as well as their PC1, PC2 and PC3 (Vinther et al., 2010) for the period 19081970. (b) Filtered (7-year running mean) PC1 of stable isotopes (black) and blocking index (red).

During summer the Atlantic and Pacific regions present a reduced blocking activity while Europe and western Asia regions show increases in blocking frequency (Barriopedro et al., 2006). This is shown in Fig. 10. However, the longitudinal distribution of blocking-like circulations during summer still indicates a relatively high (low) frequency of blocking in the Atlantic-European sector $\left(20^{\circ} \mathrm{W}-30^{\circ} \mathrm{E}\right)$, during cold (warm) summer conditions in southwestern Greenland (Fig. 10).

Based on the distribution represented in Fig. 10, we construct a blocking index as follows. The sector $\left(20^{\circ} \mathrm{W}-30^{\circ} \mathrm{E}\right)$ is considered to be blocked if at least five consecutive longitudes (longitude interval is $2.5^{\circ}$ ) are blocked for at least five consecutive days. The blocking index is defined as the number of days in a summer when this sector was blocked according to the above criteria. We are again interested in the temperature and blocking relationship. The temperature index (Fig. 11a) and the blocking index (Fig. 11b) are significantly negatively correlated at interannual time scale. The correlation is maximum $(r=-0.40)$ when the time delay between the two indices is zero. At decadal time scales, the in-phase correlation $(\mathrm{lag}=0)$ is -0.50 and increases to -0.62 when blocking leads the temperature with $3-5$ years. High blocking activity during 1930-1940, 1950-1960 and 1970-1980 is accompanied by relatively low temperatures in southwestern 

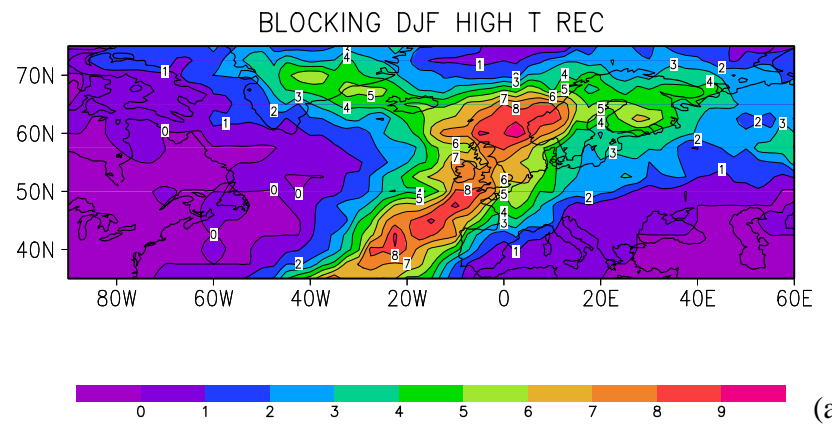

(a)

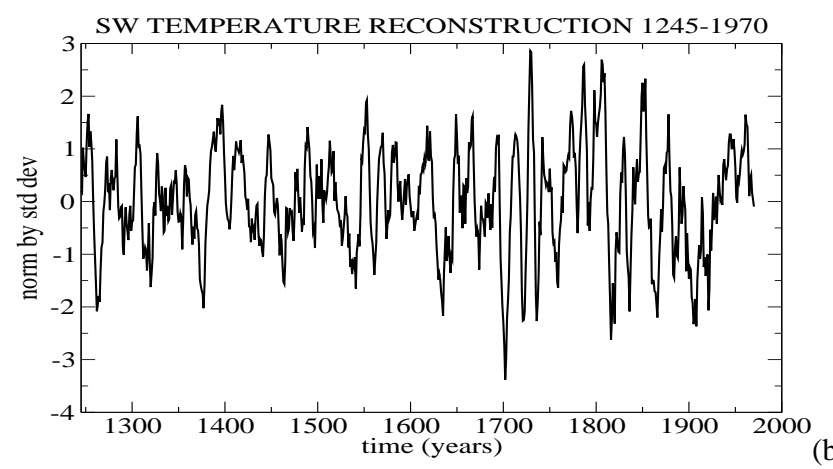

(b)

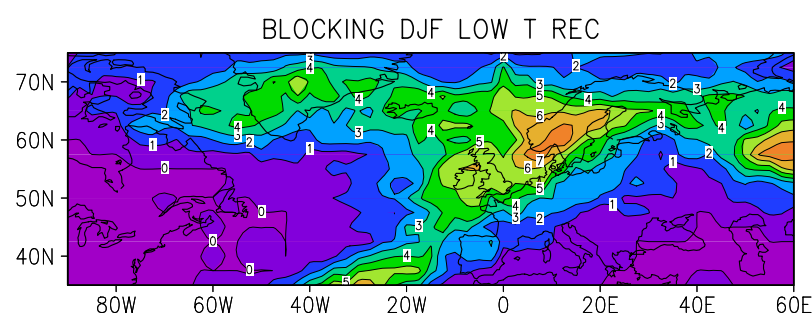

(c)

Fig. 9. Composite map of winter blocking corresponding to (a) high and (c) low values of Greenland temperature reconstruction based on stable isotopes records from Greenland ice-cores (Vinther et al., 2003) represented in $(\mathbf{b})$.

Greenland (Fig. 11). Also in this case, blocking variability is linearly related with a part of SW Greenland temperature variability. Other processes should be considered to explain the entire interannual and decadal SW Greenland temperature variability.

To have an intuitive idea on how summer blocking and Greenland temperature anomalies are related, we show (Fig. 12) the $500 \mathrm{mb}$ circulation pattern from 26 June 1972 when a strong blocking event occurred in the Scandinavian region. The 1972 summer was one of the coldest in the analysed period (Fig. 11a). For this particular day, the blocking pattern from Scandinavia is accompanied westward by a low pressure system that favours advection of cold air from the north toward southern Greenland and, therefore, low temperatures in the region (Fig. 12). If such a type of circulation

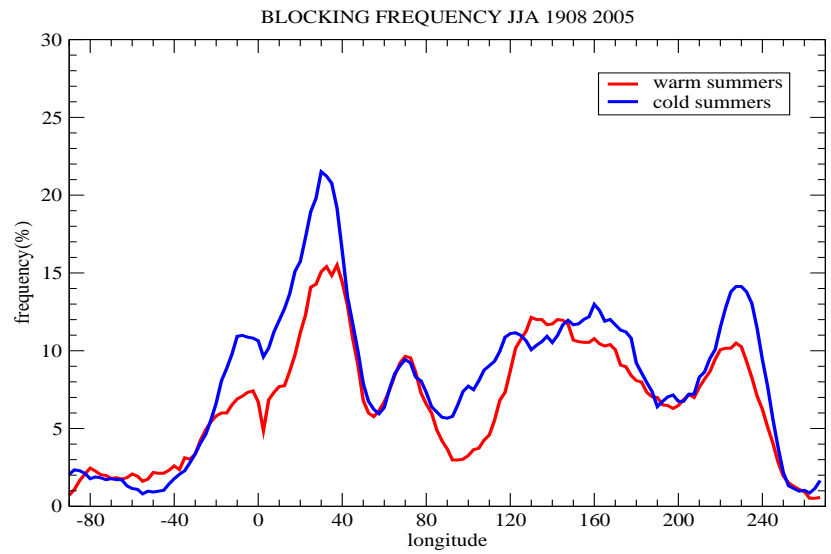

Fig. 10. Frequency composites of blocked days for warm (red) and cold (blue) summers in southwestern Greenland.
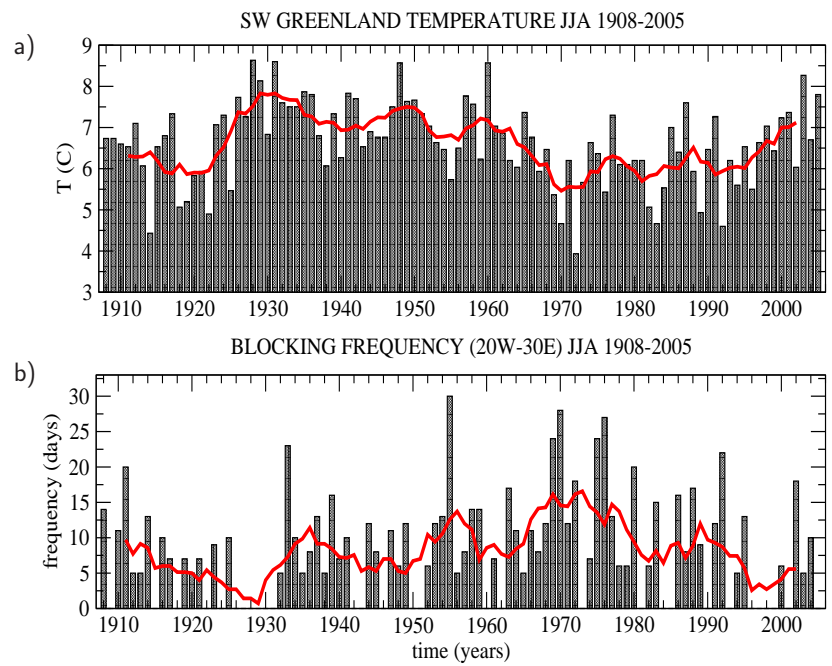

Fig. 11. (a) Southwestern Greenland temperature index during summer (Vinther et al., 2006) (bar) and its decadal variation (7-year running mean) (red) for the period 1908 to 2005. (b) Blocking index (bar) and its decadal variations (7-year running mean) (red) for the same period.

persists over many days, which is usually the case, or occurs frequently within a certain summer, Greenland will experience low mean summer temperature. Therefore, high (low) blocking activity in the Scandinavian region will be associated with cold (warm) conditions in Greenland.

Following the same methodology as in the case of the winter months, we calculate the frequency of blocking in each grid point, using the algorithm described by Scherrer et al. (2006). High frequency of blocking is recorded over eastern Greenland as well as over a large area in the Scandinavian region (Fig. 13). When the data are stratified for warm and cold summers, important changes in the blocking distribution appear (Fig. 14). During warm summers, the frequency of blocking is relatively high in the eastern 


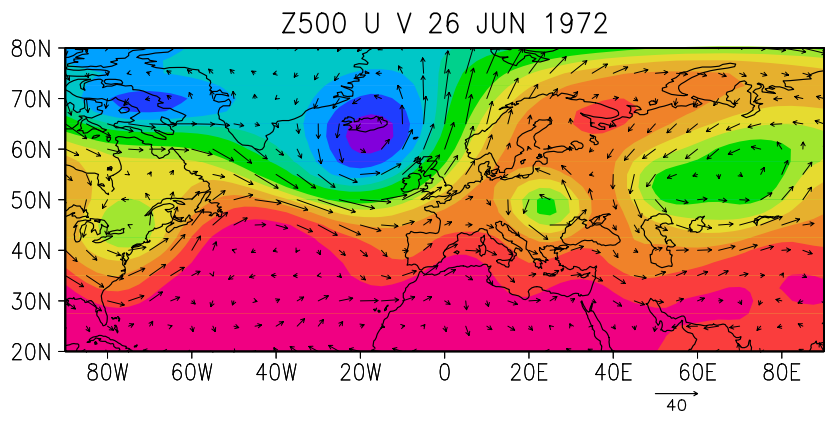

$\begin{array}{lllllllllll}5300 & 5350 & 5400 & 5450 & 5500 & 5600 & 5650 & 5700 & 5750 & 5800 & 5850\end{array}$

Fig. 12. Upper atmospheric circulation $(500 \mathrm{mb})$ for the blocking event from 26 June 1972. Colour (Z500), vector (wind). Units are $\mathrm{m}$ and $\mathrm{ms}^{-1}$.
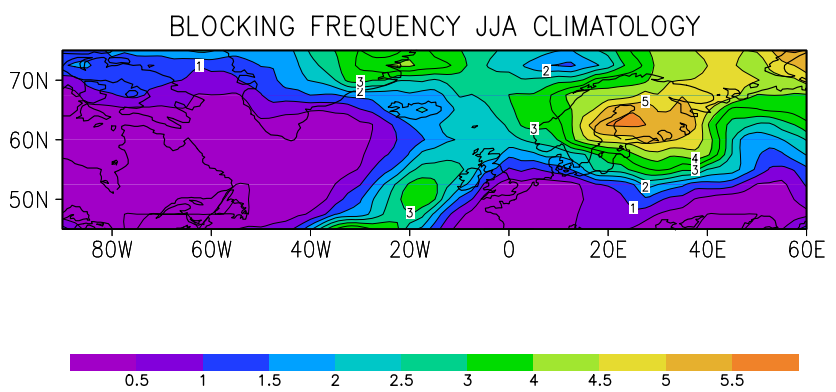

Fig. 13. Euro-Atlantic summer blocking frequency climatology of 5-day persistent blocking using the Scherrer et al. (2006) blocking indicator. Units are percentage of blocked days to total number of days per summer. Period is 1908-2005.

Greenland region (6-7\%) and in the Scandinavian region (Fig. 14a). Cold summers (Fig. 14c) are characterised by enhanced blocking frequency over the Scandinavian region ( $8 \%$ of days are blocked). The SW Greenland time series (Fig. 14b) shows strong decadal variations. The very low temperatures from 1820s suggest enhanced blocking over the Scandinavian region during this period as shown in Fig. 14c.

The summer blocking index (Fig. 11b), which was defined based on SW Greenland temperature, is relatively low correlated with most of the summer stable isotope records from Greenland ice cores (Vinther et al., 2010). Only the correlation coefficient between summer blocking index and GISP2 record is above $95 \%$ significance level (not shown). This is due to the fact that the correlation between southern Greenland temperature and stable isotope records from Greenland during summer is relatively small (Vinther et al., 2010). However, the summer blocking circulation could influence the variability of stable isotope records from Greenland ice cores through many other processes. The PC1 of the summer stable isotope time series from Greenland (Vinther et al., 2010) shows important decadal variations during the period 1786-1970 (Fig. 15b). High values of PC1 are associated
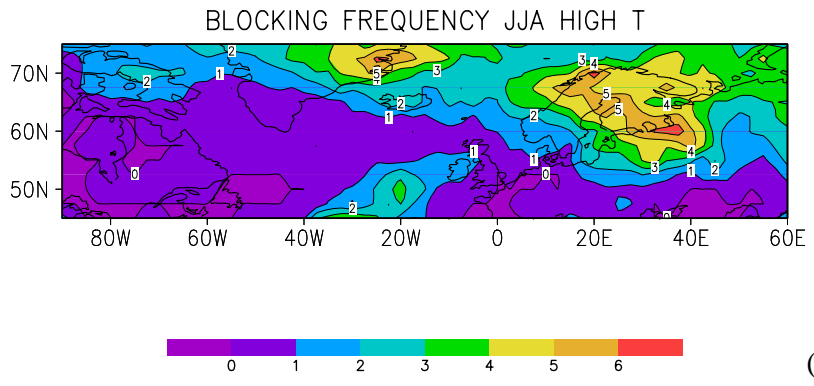

(a)
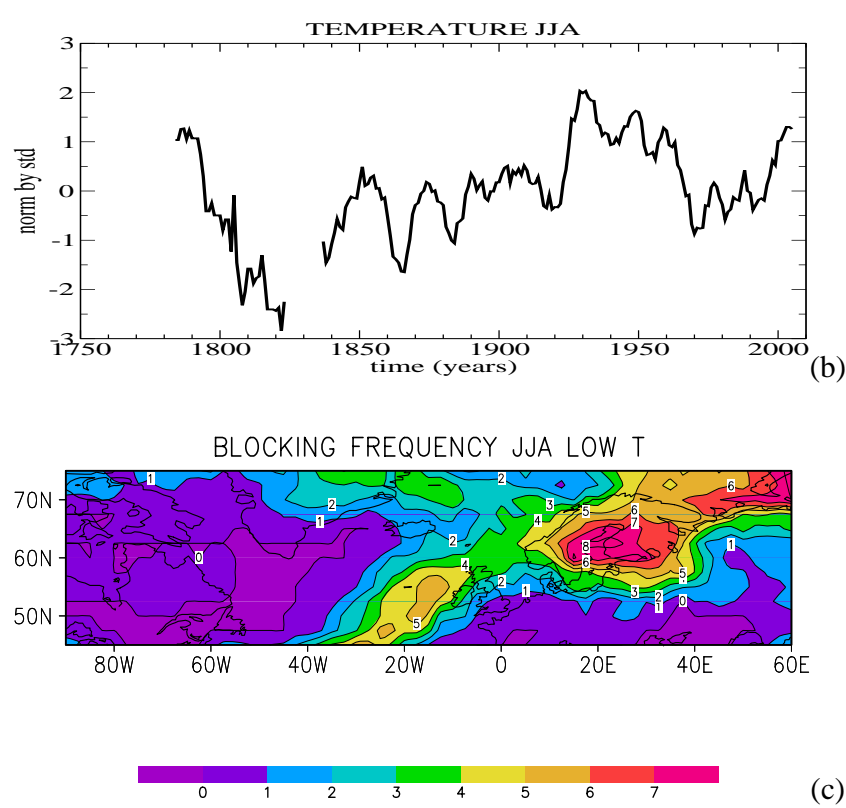

(c)

Fig. 14. (a) Blocking frequency composite for (a) high and (c) low southwestern Greenland temperatures during summer. (b) Filtered (7-year running mean) summer temperature time series for 1784 2005 period.

with high frequency of blocking over northeastern Europe (Fig. 15a) while low values of PC1 with high blocking frequency over Scandinavia (Fig. 15c). The low values of PC1 around 1830 and 1860 (Fig. 15b) suggest high blocking frequency over Scandinavia which is consistent with low temperatures in SW Greenland (Fig. 14b) and the associated blocking pattern (Fig. 14c). Similar analyses could be performed for each individual summer stable isotope record or PC2 and PC3 from the Vinther el al. (2010) dataset.

\section{Discussion and conclusions}

The relationship between temperature variability in southwestern Greenland and atmospheric blocking variability has been investigated in this paper. We have shown that for winter season high (low) temperature in southwestern Greenland is related with positive (negative) blocking frequency anomalies in the Atlantic sector, $\left(80^{\circ} \mathrm{W}-10^{\circ} \mathrm{W}\right)$. A North Atlantic 

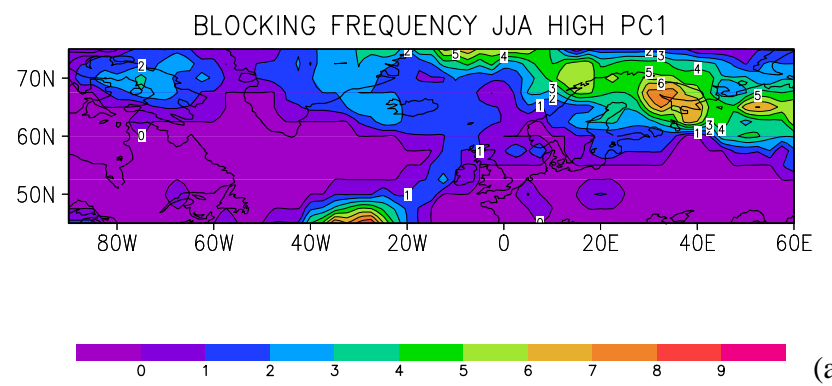

(a)
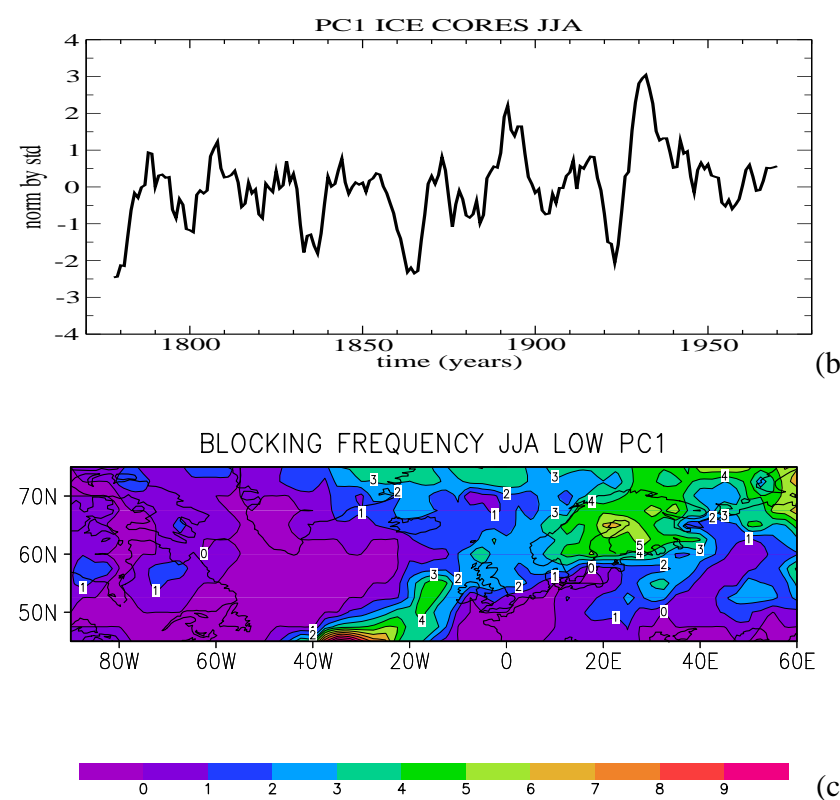

(c)

Fig. 15. (a) Blocking frequency composite for (a) high PC1 and (c) low PC1 of summer Greenland stable isotope records (Vinther et al., 2010). (b) Filtered (7-year running mean) PC1 of summer Greenland stable isotope time series for 1778-1970 period.

blocking index, which is significantly positively correlated with SW Greenland temperature index, shows pronounced decadal variations during the 1908-2005 period. This index shows low blocking activity from 1908 to 1935 with a small period of relatively high blocking frequency around 1916 (Fig. 2b). Previous studies (Parker et al., 1994; Hurrell et al., 2003) described 1901-1930 as a period of increased westerly winds and cyclonicity over the mid-latitude North Atlantic. Strong zonal circulation during 1920-1930 was identified by Makrogiannis et al. (1982). The 1920s was a period of increased cyclone activity in the North Atlantic with the exception of some increase in blocking activity around 1920 (Slonosky et al., 2000). The low blocking activity is consistent with predominantly positive values of the NAO index during this period (Rogers, 1984). The blocking decadal variability after 1948 as obtained here (Fig. 2b) is similar with the blocking variability as presented in previous studies (e.g., Barriopedro et al., 2006). However, here we present quantitative measures of both blocking frequency and blocking spatial distributions also in the early part of the 20th century. The relatively high overlap of periods of high (low) blocking activity in the North Atlantic and high (low) temperature anomalies in SW Greenland (Fig. 2) suggests to use SW Greenland temperature anomalies as a proxy for North Atlantic blocking variability. Using long-term observational temperature records from this region (Vinther et al., 2006), we obtained information related to blocking variability in the Atlantic sector back to 1784 .

The blocking activity during the last two hundred years was discussed based on the PC1 of several stable isotope time series from shallow Greenland ice cores which follow similar decadal variations $(r=0.83)$ with observed SW Greenland temperature (Vinther et al., 2010). The variable position of moisture sources during different phases of the NAO gives a stronger NAO signal in Greenland ice cores (Sodemann et al., 2008) than the variability of SST associated with the two NAO phases. As the NAO is related to blocking (e.g., Shabbar et al., 2001) this mechanism could explain the relationship of blocking and stable isotope variability as established in our study. The stable isotope variability from Greenland is related also to the variability of the frequency of several daily atmospheric circulation patterns which control the fractionation processes during the way of the associated air masses toward Greenland (Rimbu and Lohmann, 2010). However, the relationship between stable isotope variability from Greenland and blocking is rather complex. It is beyond the goal of our study to investigate the physical process that explain statistical relationships between blocking variability and stable isotope variability from Greenland.

Given the relationship between SW Greenland temperature and blocking established for the instrumental period, temperature reconstructions from Greenland ice cores are useful to put the blocking variability during the last two hundred years into a longer-term perspective. Both the PC1 of 14 stable isotope records from Greenland (Fig. 8b) and the southern Greenland temperature reconstruction (Fig. 9b) show a pronounced spectral peak at bidecadal time scale (not shown). Such a peak was detected in various ice core records from Greenland (e.g., Hibler and Johnsen, 1979). Based on the results presented in this study, we suggest that both intensity and position of the main blocking centres in the AtlanticEuropean region follow also bidecadal variations.

The southern Greenland temperature reconstruction (Fig. 9b) shows extremely cold temperatures around 1700 which is indicative of high blocking over Europe and in the Ural mountains region (Fig. 9c). During the period 16751715, referred to as the Late Mounder Minimum (LMM), solar radiation was extremely low and Europe experienced persistent, extremely cold winters (Luterbacher et al., 2001). Strong phases of increased ice from 1655 to 1710 were detected (Koslowski and Glaser, 1999) which is indicative of high blocking activity. The synoptical comparisons with current conditions have shown that LMM winters were characterised by significant high pressure over northern Europe 
accompanied by below normal pressure over the Mediterranean (Luterbacher et al., 2001; Xoplaki et al., 2001). Such a pattern matches the Atlantic-European blocking (Trigo et al., 2004). Pronounced blocking activity from 1670 to 1700 was identified from climate regime analysis of reconstructed and modelled data (Casty et al., 2005). In a recent study, Barriopedro et al. (2008) argued that solar activity plays an essential role in modulating the blocking parameters with the strongest signal in the Atlantic sector. High solar activity is connected with extensive blocking locations, less persistent blocks and a more zonally extended blocking pattern.

We have shown that blocking frequency in the AtlanticEuropean $\left(30^{\circ} \mathrm{W}-30^{\circ} \mathrm{E}\right)$ sector is enhanced during cold conditions in southwestern Greenland during summer. Because persistent blocks occur during low temperatures in southwestern Greenland, we speculate that the extreme phenomena which accompany such blocks (Trigo et al., 2004) were more frequent during these periods. Long-term observational data from SW Greenland (Vinther et al., 2006) shows very low summer temperatures around 1830 (Fig. 14b) suggesting high blocking activity over Scandinavia during this period. Enhanced blocking activity over Scandinavia during this period is suggested also by low values of PC1 of summer stable isotope records from Greenland (Fig. 15). During summer stable isotope variability is controlled not only via temperature, but also via fractionation processes associated to atmospheric circulation and related precipitation processes (Rimbu and Lohmann, 2010). Proxy data of summer temperature from southwestern Greenland can be used to put the summer blocking variability from this sector into a long-term context.

The combination of high-resolution (daily) atmospheric circulation datasets and long-term seasonally resolved climate variables allows to obtain relevant information about blocking activity during past periods. The reconstruction of synoptic scale activity from long-term observed and proxy data as presented in this study can provide a better interpretation of the connection between proxy data and atmospheric circulation variability than the traditional atmospheric teleconnection approach, especially for extreme phenomena.

Acknowledgements. This study was funded by the Alfred Wegener Institute for Polar and Marine Research, Bremerhaven, Germany through the PACES and ESSReS program as well as KARSTHIVES Project funded by CNCSIS UEFISCSU, project IDEI 31/2010. We thank the reviewers for their constructive comments.

Edited by: V. Masson-Delmotte

\section{References}

Appenzeller, C., Stocker, T. F., and Anklin, M.: North Atlantic Oscillation dynamics recorded in Greenland ice cores, Science, 282, 446-449, 1998.

Barriopedro, D., Herrera, R. G., Lupo, A. R., and Hernández, E.: A climatology of Northern Hemisphere blocking, J. Climate, 19, 1042-1063, 2006.

Barriopedro, D., García-Herrera, R., and Huth, R.: Solar modulation of Northern Hemisphere winter blocking, J. Geophys. Res., 113, D14118, doi:10.1029/2008JD009789, 2008.

Casty, C., Handorf, D., Raible, C. C., González-Rouco, J. F., Weisheimer, A., Xoplaki, E., Luterbacher, J., Dethloff, K., and Wanner, H.: Recurrent climate winter regimes in reconstructed and modelled $500 \mathrm{hPa}$ geopotential height fields over the North Atlantic/European sector 1659-1990, Clim. Dynam., 24(7-8), 809-822, doi:10.1007/s00382-004-0496-8, 2005.

Compo, G. P., Whitaker, J. S., and Sardeshmukh, P. D.: Feasibility of a 100 year reanalysis using only surface pressure data, B. Am. Meteorol. Soc., 87, 175-190, 2006.

Compo, G. P., Whitaker, J. S., Sardeshmukh, P. D., Matsui, N., Allan, R. J., Yin, X., Gleason, B. E., Vose, R. S., Rutledge, G., Bessemoulin, P., Brönnimann, S., Brunet, M., Crouthamel, R. I., Grant, A. N., Groisman, P. Y., Jones, P. D., Kruk, M., Kruger, A. C., Marshall, G. J., Maugeri, M., Mok, H. Y., Nordli, Ø., Ross, T. F., Trigo, R. M., Wang, X. L., Woodruff, S. D., and Worley, S. J.: The Twentieth Century Reanalysis Project, Q. J. Roy. Meteorol. Soc., 137, 1-28, doi:10.1002/qj.776, 2011.

Croci-Maspoli, M., Schwierz, C., and Davies, H. C.: Atmospheric blocking: space-time links to the NAO and PNA, Clim. Dynam., 29(7-8), 713-725, doi:10.1007/s00382-007-0259-4, 2007.

Crüger, T., Fischer, H., and von Storch, H.: What do accumulation records of single ice cores in Greenland represent?, J. Geophys. Res., 109, D21110, doi:10.1029/2004JD005014, 2004.

D’Andrea, F., Tibaldi, S., Blackburn, M., Boer, G., Déqué, M., Dix, R., Dugas, B., Ferranti, L., Iwasaki, T., Kitho, A., Pope, V., Randall, D., Roeckner, E., Straus, D., Stem, W., van den Dool, H., and Williamson, D.: Northern Hemisphere Atmospheric Blocking as simulated by 15 Atmospheric General Circulation Models in the period 1979-1988, Clim. Dynam., 14, 385-407, 1998.

Diao, Y., Li, J., and Luo, D.: A new blocking index and its application: blocking action in the Northern Hemisphere, J. Climate, 19, 4819-4839, 2006.

Hanna, E., McConnell, J., Das, S., Cappelen, J., and Stephens, A.: Observed and modeled Greenland ice sheet snow accumulation, 1958-2003, and links with regional climate forcing, J. Climate, 19, 344-358, 2006.

Hibler, W. D. and Johnsen, S. J.: The $20-y r$ cycle in Greenland ice core records, Nature, 280, 481-483, 1979.

Hurrell, J. W., Kushnir, Y., Visbeck, M., and Ottersen, G.:, The North Atlantic Oscillation: Climate Significance and Environmental Impact, in: An Overview of the North Atlantic Oscillation, edited by: Hurrell, J. W., Kushnir, Y., Ottersen, G., and Visbeck, M., Geophys. Monogr. Ser., 134, 1-35, 2003.

Jones, P. D., Jonsson, T., and Wheeler, D.: Extension to the North Atlantic Oscillation using early instrumental pressure observations from Gibraltar and South-West Iceland, Int. J. Climatol., 17, 1433-1450, 1997. 
Kalnay, E., Kanamitsu, M., Kistler, R., Collins, W., Deaven, D., Gandin, L., Iredell, M., Saha, S., White, G., Woollen, J., Zhu, Y., Chelliah, M., Ebisuzaki, W., Higgins, W., Janowiak, J., Mo, K. C., Ropelewski, C., Wang, J., Leetmaa, A., Reynolds, R., Jenne, R., and Joseph, D.: The NMC/NCAR 40-Year eanalysis Project, B. Am. Meteorol. Soc., 77, 437-471, 1996.

Koslowsky, G. and Glaser, R.: Variations in Reconstructed Ice Winter severity in the Western Baltic from 1501 to 1995 , and their Implications for the North Atlantic Oscillation, Climatic Change, 41, 175-191, 1999.

Luo, D. and Wan, H.: Decadal variability of wintertime North Atlantic and Pacific blockings: A possible cause, Geophys. Res. Lett., 32, L23810, doi:10.1029/2005GL024329, 2005.

Luterbacher, J., Rickli, R., Xoplaki, E., Tinguely, C., Beck, C., Pfister, C., and Wanner, H.: The late Mounder Minimum (16751715) - a key period for studying decadal scale climatic change in Europe, Climatic Change, 49, 441-462, 2001.

Makrogiannis, T. J., Bloutsos, A. A., and Giles, B. D: Zonal index and circulation change in the North Atlantic area, 1873-1972, J. Climatol., 2, 159-169, 1982.

Parker, D. E., Jones, P. D., Folland, C. K., and Bevan, A.: Interdecadal changes of surface temperature since the late nineteenth century, J. Geophys. Res., 99, 14373-14399, 1994.

Rimbu, N. and Lohmann, G.: Decadal variability in a central Greenland high-resolution deuterium isotope record and its relationship to the frequency of daily atmospheric circulation patterns from the North Atlantic region, J. Climate, 23, 4608-4618, doi:10.1175/2010JCLI3556.1, 2010.

Rimbu, N., Lohmann, G., and Grosfeld, K.: Blocking signature in ice core records from northern Greenland, Geophys. Res. Lett., 34, L09704, doi:10.1029/2006GL029175, 2007.

Rogers, J. C.: The association between the North Atlantic Oscillation and the Southern Oscillation in the northern Hemisphere, Mon. Weather Rev., 112, 1999-2015, 1984.

Rogers, J. C., Bolzan, J. F., and Pohjola, V. A.: Atmospheric circulation variability associated with shallow-core seasonal isotopic extremes near Summit, Greenland, J. Geophys. Res., 103(D10), 11205-11219, doi:10.1029/98JD00591, 1998.

Saha, S., Nadiga, S., Thiaw, C., Wang, J., Pan, H.-L., Moorthi, S., Behringer, D., Stokes, D. , Peña, M., Lord, S., White, G., Ebisuzaki, W., Peng, P., and Xie, P.: The NCEP Climate Forecast System, J. Climate, 19, 3483-3517, 2006.

Scherrer, S. C., Croci-Maspoli, M., Schwierz, C., and Appenzeller, C.: Two-dimensional indices of atmospheric blocking and their statistical relationship with winter climate patterns in the EuroAtlantic region, Int. J. Climatol., 26, 233-249, 2006.
Shabbar, A., Huang, J., and Higuchi, K.: The relationship between the wintertime North Atlantic Oscillation and blocking episodes in the North Atlantic, Int. J. Climatol., 21, 355-369, 2001.

Sodemann, H., Masson-Delmotte, V., Schwierz, C., Vinther, B. M., and Wernli, H.: Interannual variability of Greenland winter precipitation sources: 2. Effects of North Atlantic Oscillation variability on stable isotopes in precipitation, J. Geophys. Res., 113, D1211, doi:10.1029/2007JD009416, 2008.

Slonosky, V. C., Jones, P. D., and Davies, T. A.: Variability of the surface atmospheric circulation over Europe, 1774-1995, Int. J. Climatol., 20, 1875-1897, 2000.

Tibaldi, S. and Molteni, F.: On the operational predictability of blocking, Tellus A, 42, 343-365, 1990.

Tibaldi, S., D’Andrea, F., Tosi, E., and Roeckner, E.: Climatology of the northern hemisphere blocking in the ECHAM model, Clim. Dynam., 13, 649-666, 1997.

Treidl, R. A., Birch, E. C., and Sajecki, P.: Blocking action in the Northern Hemisphere: a climatological study, Atmos.-Ocean, 19, 1-23, 1981.

Trigo, R. M., Trigo, I. F., DaCamara, C. C., and Osborn, T. J.: Climate impact of the European winter blocking episodes from NCEP/NCAR Reanalysres, Clim. Dynam., 23, 17-28, 2004.

Vinther, B. M., Johnsen, S. J., Andersen, K. K., Clausen, H. B., and Hansen, A.W.: NAO signal recorded in the isotopes of Greenland ice cores, Geophys. Res. Lett., 30, 1387, doi:10.1029/2002GL016193, 2003.

Vinther, B. M., Andersen, K. K., Jones, P. D., Briffa, K. R., and Cappelen, J.: Extending Greenland temperature records into the late eighteenth century, J. Geophys. Res., 111, D11105, doi:10.1029/2005JD006810, 2006.

Vinther, B. M., Jones, P. D., Briffa, K. R., Clausen, H. B., Andersen, K. K., Dahl-Jensen, D., and Johnsen, S. J.: Climatic signals in multiple high resolved stable isotope records from Greenland, Quaternary Sci. Rev., 29, 522, 2010.

Whitaker, J. S., Compo, G. P., Wei, X., and Hamill, T. M.: Reanalysis without radiosondes using ensemble data assimilation, Mon. Weather Rev., 132, 1190-1200, 2004.

Xoplaki, E., Maheras, P., and Luterbacher, J.: Variability of climate in meridional Balkans during the periods 1675-1715 and 17801830 and its impact on human life, Climatic Change, 48, 581614, 2001.

Zhifang, F. and Wallace, J. M.: The relationship between the wintertime blocking over Greenland and the sea ice distribution over North Atlantic, Adv. Atmos. Sci., 10, 453, 1993. 